\title{
Sex in der Arztpraxis
}

\section{Intimitäten mit Patienten sind tabu}

\author{
Sexuelle Kontakte zwischen Ärzten und Patienten kommen immer wieder vor. Gefährliche Liebschaften, \\ denn selbst wenn eine Patientin mit dem Sex einverstanden war, können Ärzte, Heilpraktiker und \\ Betreuer wegen sexuellen Missbrauchs belangt werden. Wann genau ist die Grenze zur Straftat erreicht?
}

E s sind meist die spektakulären Fälle, die Aufmerksamkeit erregen. So das Strafverfahren gegen einen Gynäkologen, der Patientinnen betäubte und dann vergewaltigte. Jüngst wurde der Fall eines Heilpraktikers bekannt, der den unerfüllten Kinderwunsch einer Patientin mit Sex „behandelte“. Zu seiner „Therapie“ gehörte das Heranführen seines Penis an den Mund der Patientin, ein Biss in deren linke Brust sowie einvernehmlicher Oralund Geschlechtsverkehr. Das Landgericht Münster sprach den Mann bezüglich der einvernehmlichen Taten vom Vorwurf des Missbrauchs frei und verurteilte ihn wegen des Bisses und des Heranführens des Penis zu einer Bewährungsstrafe von 16 Monaten. Aber auch eine Verurteilung aufgrund der einvernehmlichen sexuellen Handlungen sei nicht ausgeschlossen. Der BGH hob das Urteil des Landgerichts auf und reichte den Fall zur weiteren Aufklärung zurück.

\section{Strafbar auch ohne Gewalt}

Immer wieder kommt es auch ohne Gewalt zu Beziehungen und Grenzverletzungen zwischen Ärzten und Patienten. Wie aber haben sich Ärzte korrekt zu verhalten? Wann beginnt eine unangemessene oder zu lange Berührung oder eine Berührung an Körperstellen, die aus medizinischer Sicht nicht zu rechtfertigen sind?

$\S 174$ c Absatz 1 STGB stellt den sexuellen Missbrauch unter Ausnutzung eines Beratungs-, Behandlungs- oder Betreuungsverhältnisses unter Strafe. Seit das Gesetz 1998 eingeführt wurde hat es allerdings nur wenige Verurteilungen gegeben. Dennoch kann schon der Vorwurf eines sexuellen Übergriffs oder eine Beziehung bei gleichzeitiger Heilbehandlung für Ärzte gravierende Folgen haben. Selbst wenn erkennbar kein strafrechtlich relevantes Verhalten wie Vergewaltigung, sexuelle Nötigung oder Missbrauch vorliegt, kann gegen Berufsrecht verstoßen werden. Je nach Sachlage

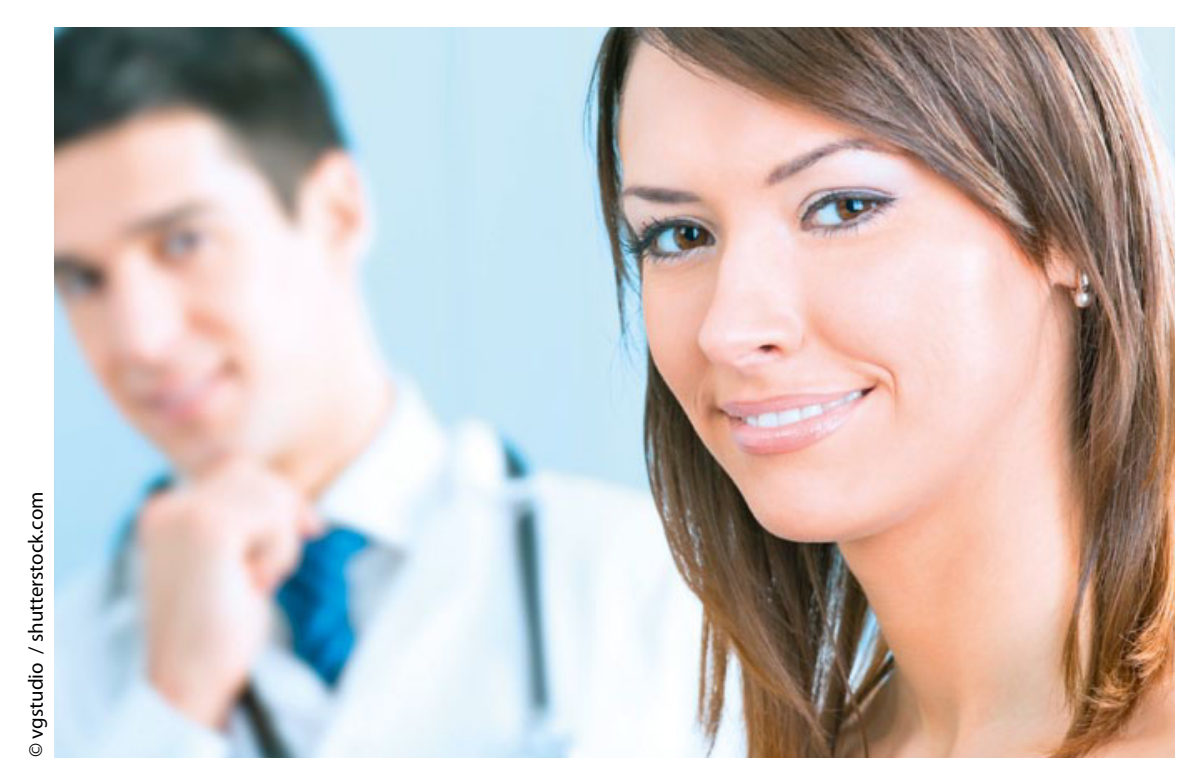

Nicht mal daran denken: Sex zwischen Arzt und Patient sollte tabu sein.

kann sogar die Approbation entzogen werden. In den ausschließlich berufsrechtlich relevanten Fällen setzten Ärzte auch nach dem Ende der Behandlung die gewaltfreie sexuelle Beziehung fort. Wird die Beziehung dann beendet, reagieren Patienten hin und wieder mit Enttäuschung und versuchen, sich zu rächen. Die Folge sind Anzeigen und zivilrechtliche Klagen auf Schmerzensgeld. Es erfolgt so eine systematische Rufschädigung der betroffenen Ärzte, ohne dass deren Schuld feststeht.

\section{Bei Beziehung Behandlung beenden}

Wenn sich eine sexuelle Beziehung anbahnt oder eingetreten ist, muss entschlossen und konsequent gehandelt werden. Hierzu gehört auf jeden Fall der sofortige Abbruch der Behandlung.

Private Treffen außerhalb der Arztpraxis exkulpieren Ärzte rechtlich keineswegs (das Amtsgericht Würzburg verurteilte einen Stationsarzt nach $\$ 174 \mathrm{c}$ StGB, obwohl die sexuellen Kontakte mit der Patientin alle außerhalb der Klinik erfolgten). Vorsicht ist geboten mit finanziellen $\mathrm{Zu}$ wendungen. So hatte ein Arzt in einem Beratungsfall mit einer Patientin eine zivilrechtliche Regelung mit hohem Schmerzensgeld vereinbart. Nach Zahlung des Geldes zeigte die Patientin den Arzt bei Kammer und Staatsanwaltschaft an. Dass die Vereinbarung die Verpflichtung der Patientin enthielt, keine Anzeigen zu erstatten, war juristisch unwirksam. Hilfreich kann hingegen eine schriftliche Aussage des Patienten sein, wonach die sexuelle Beziehung freiwillig und aus Zuneigung erfolgt ist. Eventuell kann man eine Arzthelferin ins Vertrauen ziehen, die bei dem Schlussgespräch (und bei der schriftlichen Erklärung) als Zeugin anwesend ist.

Dr. Frank A. Stebner

Fachanwalt für Medizinrecht 